\title{
Speech and Prosody Characteristics of Adolescents and Adults With High-Functioning Autism and Asperger Syndrome
}

Law rence D. Shriberg University of W isconsinMadison

Rhea Paul Yale Child Study Center and

Southern Connecticut State University $\mathrm{N}$ ew Haven, CT

Jane L. McSweeny University of $W$ isconsinMadison

Ami Klin Donald J. Cohen Fred R. Volkmar Yale Child Study Center $\mathrm{N}$ ew Haven, CT
Speech and prosody-voice profiles for 15 male speakers with High-Functioning A utism (HFA) and 15 male speakers with Asperger syndrome (AS) were compared to one another and to profiles for 53 typically developing male speakers in the same 10- to 50-years age range. Compared to the typically developing speakers, significantly more participants in both the HFA and AS groups had residual articulation distortion errors, uncodable utterances due to discourse constraints, and utterances coded as inappropriate in the domains of phrasing, stress, and resonance. Speakers with AS were significantly more voluble than speakers with HFA, but otherwise there were few statistically significant differences between the two groups of speakers with pervasive developmental disorders. Discussion focuses on perceptual-motor and social sources of differences in the prosody-voice findings for individuals with Pervasive Developmental Disorders as compared with findings for typical speakers, including comment on the grammatical, pragmatic, and affective aspects of prosody.

KEY WORDS: articulation, Asperger syndrome, autism, phonology, prosody

$\mathrm{P}$ ervasive Developmental Disorders (PDD) are a group of severe neuropsychiatric conditions characterized by disturbances in social, cognitive, and communicative function that are not fully explained by developmental level. Although most of these disorders are associated with depressed cognitive and language functioning - in $40 \%$ of cases they are accompanied by mutism (Lord \& Paul, 1997)-approximately $20 \%$ of individuals with these syndromes function within the normal range on IQ testing (American Psychiatric Association, 1994; Klin \& Volkmar, 1997). These latter individuals demonstrate large spoken vocabularies and apparently intact formal language skills. Deficits are in the areas of pragmatics and social communication (Tager-Flusberg, 1995).

Two diagnoses are associated with the profile of normal IQ and welldeveloped formal language in individuals with PDD: High-Functioning Autism (HFA) and Asperger syndrome (AS). Individuals with HFA have histories of delayed language development and symbolic play evidenced before age 3; qualitative impairments in social interactions; qualitative abnormalities in communication after early childhood despite adequate formal language skills; and restricted, repetitive, or stereotypic interests and behavioral patterns (American Psychiatric Association, 1994). Individuals with AS do not have a history of delayed language 
development, but do show the qualitative impairments in social interaction, play, and communication usually associated with autism, as well as intense circumscribed interests or obsessions, repetitive and stereotypic behavior patterns, and some motor delay and clumsiness (American Psychiatric Association, 1994; Klin, Volkmar, \& Sparrow, 2000).

As indicated by the description above, communicative dysfunction is one of the core symptoms of autistic syndromes in individuals who speak. The disjunction between intact form and impaired function has been the subject of a large literature in the language characteristics of individuals with HFA (see Landa, 2000; Lord \& Paul, 1997; Tager-Flusberg, 1995, for reviews). Fewer studies have described the phonological characteristics of individuals with autistic syndromes. This report focuses on the segmental and suprasegmental aspects of the speech of adolescents and adults with HFA and AS.

\section{Speech and Prosody}

Segmental aspects of speech sound production concern a speaker's articulatory precision. Suprasegmental aspects of speech production, or prosody, are concerned with those properties of the speech signal that modulate and enhance its meaning. Prosody functions at several levels to enable speakers to construct discourse through expressive language. Crystal (1986), Kent and Read (1992), Merewether and Alpert (1990), and Panagos and Prelock (1997) provide various accounts of these levels, which can be categorized in three subdomains.

Grammatical prosody includes suprasegmental cues that are used to signal syntactic information within sentences (Warren, 1996). Stress can be used grammatically within words to signal, for example, whether a token is being used as a noun (pre'sent) or a verb (present'). Pitch contours signal the ends of utterances and denote whether they are questions (rising pitch) or statements (falling pitch). Grammatical uses of prosody are generally obligatory aspects of the production of the surface structure that are an inherent part of the transformation from deep structure meanings (Gerken, 1996; Gerken \& McGregor, 1998).

Pragmatic prosody is used to carry social information beyond that conveyed by the syntax of the sentence. It conveys the speaker's intentions, or the hierarchy of information within the utterance, and results in optional changes in the way an utterance is expressed (Van Lancker, Canter, \& Terbeek, 1981; Winner, 1988). Stress, as one example, can be used to highlight an element of information within a sentence as the focus of attention. This pragmatic use of stress, usually referred to as emphatic or contrastive stress, calls the listener's attention to information that is new to the conversation, unfamiliar, or unexpected within the sentence. Emphatic stress is used to highlight the comment or predicate of an utterance, the portion that elaborates on the topic established within the discourse (Bates \& McWhinney, 1979; Haviland \& Clark, 1974).

Finally, affective prosody serves more global functions than those subserved by the prior two forms. Affective prosody includes both the modal register of the individual's personal speech style, as well as the changes in register used for varying social functions (e.g., differences among the ways an individual talks to peers, to young children, and to people of higher social status). Affective prosody is also involved in conveying a speaker's general feeling state (Bolinger, 1989; Hargrove, 1997). For example, a parent would produce the utterance "The children aren't home from school yet" with different suprasegmental characteristics, depending on whether she or he was feeling relaxed about having a few minutes remaining for other activities or anxious because the time at which the children should have arrived home was long past.

Research on individuals with unilateral brain damage (Emmorey, 1987; Heilman, Bowers, Speedie, \& Coslett, 1984; Luks, Nusbaum, \& Levy, 1998) suggests that these three functions of prosody can be differentially affected. Thus, their neurological organization may be, at least to some degree, functionally independent. Should such differences be observed, they could suggest hypotheses about mechanisms underlying speaker competence.

\section{Speech and Prosody Characteristics of Individuals W ith Pervasive Developmental Disorders}

Segmental or articulatory aspects of speech have typically been reported to be commensurate with overall developmental rates in speakers with autism or AS (Bartolucci, Pierce, Streiner, \& Eppel, 1976; Pierce \& Bartolucci, 1977; Tager-Flusberg, 1981) or somewhat delayed (Bartak, Rutter, \& Cox, 1975; Rutter, Maywood, \& Howlin, 1992). However, since the first delineation of the autistic syndrome (Kanner, 1943), abnormal suprasegmentals have been frequently identified as a core feature of the syndrome for individuals with autism who speak (Baltaxe \& Simmons, 1985, 1992; Fay \& Schuler, 1980; Ornitz \& Ritvo, 1976; Paul, 1987; Pronovost, Wakstein, \& Wakstein, 1966; Rutter \& Lockyer, 1967; Tager-Flusberg, 1981). Differences noted in early, observational reports included monotonic or machine-like intonation, deficits in the use of pitch and control of volume, deficiencies in vocal quality, and use of aberrant stress patterns. When these differences are present they tend to be persistent and to show little change over time, 
even when other aspects of language improve (DeMyer et al., 1973; Kanner, 1971; Rutter \& Lockyer, 1967; Simmons \& Baltaxe, 1975). Prosodic deficits have not been universally reported, however. Simmons and Baltaxe (1975), for example, found that only four out of the seven adolescents with autism they studied had notable suprasegmental differences in their speech. When such behaviors are present the prosody characteristics of a person with autism constitute one of the most significant obstacles to his or her social integration and vocational acceptance. Mesibov (1992) and VanBourgondien and Woods (1992) reported that it is the vocal presentation of individuals with autism that most immediately creates an impression of oddness.

It can be hypothesized that the prosodic deficits so frequently attributed to people with autistic syndromes reside primarily in the pragmatic and affective aspects of prosody, with grammatical aspects relatively spared. This hypothesis stems from two sources. A primary consideration, as cited above, is the documented grammatical and morphological strengths in individuals with HFA and AS, compared to their reduced abilities in the meaningful use of language for social communication (Landa, 2000; Tager-Flusberg, 1981, 1995). A second consideration is that the relatively large body of research on prosody in autism can be interpreted to suggest that a majority of the identified deficits reside in pragmatic or affective functions. Ricks (1975) and Lord, Rutter, and DeLavore (1996) demonstrated that parents have more difficulty identifying the emotional content of prespeech vocalization in their children with autism than do parents of children with mental retardation or normal language. Several studies (Boucher, Lewis, \& Collis, 1998; Hobson, Ouston, \& Lee, 1988, 1989; Van Lancker, Cornelius, \& Krieman, 1989) have shown that children with autism have difficulty matching vocally expressed affect to facial expressions or to emotion words (e.g., happy, sad, scared).

Table 1 is a summary of prosodic studies of individuals with HFA or AS for which it was possible to interpret grammatical versus pragmatic or affective distinctions in prosody domains. Of the nine studies in which grammatical prosodic data could be identified, only three yielded differences between the speakers with autistic syndromes and typically speaking control groups. In the 10 studies in which pragmatic or affective prosody data appear to have been involved, all the findings indicated atypical performance in participants with autistic syndromes.

Inspection of the several domains of suprasegmental performance in the studies in Table 1 suggests that findings for pauses differ when divided into their occurrence in grammatical versus pragmatic/affective context. In two studies, grammatical pausing was reportedly appropriate in children with HFA or AS, whereas pragmatic pausing was reportedly atypical. Findings for stress and pitch appear to be inconsistent, with some studies reporting deficits in grammatical as well as pragmatic contexts, and others reporting normal grammatical production. The few studies that have looked at rate, loudness, and quality report differences in what appear to be the modal registers of the subjects with HFA or AS.

From a methodological perspective, there are many constraints underlying the findings summarized in Table 1 . The number of participants included in each study has been small; most studies in Table 1 included 3 to 12 subjects. Methods used to quantify prosodic and vocal behavior have differed considerably from one another, with no study to date reporting findings obtained by means of a standardized procedure. Studies fail to provide explicit procedural information on the signals assessed for different prosodic functions. For example, several studies (Baltaxe, Simmons, \& Zee, 1984; Fine, Bartolucci, Ginsberg, \& Szatmari, 1991) purport to assess the global construct of intonation patterns, which subsumes a broad array of both signal features and prosodic functions. Other studies may focus on one prosodic construct, such as linguistic stress, but fail to discriminate among the functions (e.g., grammatical, pragmatic) it subserves (e.g., Baltaxe, 1981; Paccia \& Curcio, 1982). Also, most studies have reported averaged performance across subjects, which fails to estimate the prevalence of significant prosodic disturbances in this population compared to appropriate control groups. Thus, there presently is no consensus on the characterization of specific parameters of suprasegmental behaviors or on their role as core areas of disorder in pervasive developmental disabilities.

\section{Rationale and Study Goals}

The primary aim of the present study is to report speech and prosody-voice profiles for 30 males with HFA or AS using standardized assessment instruments and to compare findings to those documented for typical speakers of comparable ages. The instrument selected for prosody-voice assessment, The Prosody-Voice Screening Profile (PVSP; Shriberg, Kwiatkowski, \& Rasmussen, 1990), has a long history of use with a variety of communication disorders (e.g., McSweeny \& Shriberg, in press; Odell \& Shriberg, 2001; Shriberg, Aram, \& Kwiatkowski, 1997; Shriberg \& Widder, 1990), provides reference data for conversational speech samples from typical speakers (Shriberg, Kwiatkowski, Rasmussen, Lof, \& Miller, 1992), and has well-described psychometric characteristics (cf. McSweeny \& Shriberg, in press; Shriberg, Kwiatkowski, \& Rasmussen, 1990). For the primary aim of this study, it is appropriate to use the 
Table 1. Prosody-voice findings for individuals with HFA and AS.

\begin{tabular}{|c|c|c|c|}
\hline Domain & Study & Grammatical function & Pragmatic/ affective function \\
\hline \multicolumn{4}{|l|}{ Prosody } \\
\hline \multirow[t]{2}{*}{ Phrasing } & $\begin{array}{l}\text { Fine, Bartolucci, Ginsberg, } \\
\& \text { Szatmari, } 1991\end{array}$ & $\begin{array}{l}\text { HFA and AS similar to typical controls in } \\
\text { placement of pauses at grammatical boundaries } \\
\text { in speech. }\end{array}$ & \\
\hline & $\begin{array}{l}\text { Thurber \& Tager-Flusberg, } \\
1993\end{array}$ & $\begin{array}{l}\text { HFA and typical controls have similar use of } \\
\text { grammatical pausing. }\end{array}$ & $\begin{array}{l}\text { HFA have less frequent use of nongrammatical pauses, } \\
\text { thought to reflect cognitive processing and lexical } \\
\text { decision. }\end{array}$ \\
\hline Rate & Baltaxe, 1981 & & $\begin{array}{l}\text { Compared to typical speakers, HFA have longer } \\
\text { duration and more variability in production of } \\
\text { sentences; single word durations were more similar } \\
\text { to the same word durations in sentences. }\end{array}$ \\
\hline \multirow[t]{5}{*}{ Stress } & Baltaxe, 1984 & & $\begin{array}{l}\text { HFA had more misassignments of contrastive } \\
\text { stress than controls, although the total } \\
\text { number of misassignments was small. }\end{array}$ \\
\hline & Baltaxe \& Simmons, 1985 & $\begin{array}{l}\text { HFA misassigned stress to function words } \\
\text { instead of content words; stress was assigned } \\
\text { to more than one sentence element. }\end{array}$ & \\
\hline & Fay, 1969 & $\begin{array}{l}\text { HFA recalled stressed words better than unstressed, } \\
\text { particularly when stress was on content words. }\end{array}$ & \\
\hline & Fine et al., 1991 & $\begin{array}{l}\text { HFA and AS were similar to typical controls on } \\
\text { unmarked (grammatical) stress placement. }\end{array}$ & $\begin{array}{l}\text { HFA used contrastive (pragmatic) stress on content } \\
\text { words less often than AS or typical controls; AS were } \\
\text { similar to controls in stress placement. }\end{array}$ \\
\hline & McCaleb \& Prizant, 1985 & & $\begin{array}{l}\text { HFA stressed old and new information in sentences } \\
\text { with equal frequency. }\end{array}$ \\
\hline \multirow{4}{*}{ Pitch } & Fay $\&$ Schuler, 1980 & & $\begin{array}{l}\text { Some HFA speakers used "sing-song" } \\
\text { intonation. }\end{array}$ \\
\hline & Fine et al., 1991 & $\begin{array}{l}\text { HFA and AS used tone boundaries } \\
\text { adequately to locate ends of utterances. }\end{array}$ & \\
\hline & Paccia \& Curcio, 1982 & $\begin{array}{l}\text { HFA tended to use falling pitch contours in their } \\
\text { echoed responses to questions, with rising } \\
\text { intonation particularly when they understood the } \\
\text { questions and meant to answer "yes." }\end{array}$ & \\
\hline & Pronovost et al., 1966 & & $\begin{array}{l}\text { HFA speakers had wide variations in pitch; their } \\
\text { echoed speech did not mimic the intonation } \\
\text { contour of the stimulus utterance and was } \\
\text { monotonic. }\end{array}$ \\
\hline Quality & Pronovost et al., 1966 & & $\begin{array}{l}\text { HFA speakers had extensive variation from } \\
\text { normal voice quality including hoarseness, } \\
\text { harshness, and hypernasality. }\end{array}$ \\
\hline
\end{tabular}


same PVSP analytic conventions that have been used with all other clinical groups-essentially, detailed description of findings across each of the seven prosodyvoice domains.

The secondary aim of the present research is to consider the communicative profiles of the two groups of speakers with PDD relative to the three functions of prosody described previously: grammatical, pragmatic, and affective. Because the PVSP was designed as a descriptive tool for use in a variety of clinical-research contexts, the seven prosody-voice features cannot be directly mapped onto the three functions of prosody reviewed previously. Therefore, the discussion of findings will interleave perspectives on the functions of prosody within the more general consideration of speech and prosodyvoice characteristics of speakers with high-functioning autism or Asperger syndrome.

\section{$\overline{\text { Method }}$}

\section{Participants \\ HFA and AS}

A data set of 30 male participants with HFA and AS was obtained from cases seen in the Developmental Disabilities Section of the Yale Child Study Center. These individuals had completed an extensive protocol as part of two projects on the neurobiology of autism. The protocol included data from standardized assessments of cognitive, language, and social-adaptive functioning and from a videocassette recording of a conversational speech sample obtained during a semistructured diagnostic interview. Diagnostic characterization included the Autism Diagnostic Interview-Revised (ADI-R; Lord, Rutter, \& LeCouteur, 1994) and the Autism Diagnostic Observation Schedule-Generic (ADOS-G; Lord et al., 1996). Diagnostic assignment followed DSM-IV criteria for autism and AS (American Psychiatric Association, 1994). In accordance with these criteria, none of the individuals assigned the diagnosis of AS had speech and language delays or marked deviance in the first 3 years of life (Klin \& Volkmar, 1997; Volkmar et al., 1994). Clinical diagnoses were confirmed independently by two experienced clinicians (AK and FV) with demonstrated interrater reliability (Klin, Lang, Cicchetti, \& Volkmar, 2000).

Table 2 includes age and assessment information for the 30 participants. Speakers ranged in age from 10 to 49 years; 18 (60\%) were 10 to 20 years old, and the remaining $12(40 \%)$ were 20 to 49 years old. The mean ages of speakers in the HFA and AS groups, respectively, were 21.6 and 20.7 years. Statistical tests ( $t$ tests) for differences between the ages of speakers in each group, as well as for differences on all other variables in
Table 2, were nonsignificant, with the exception of two subscales of the Autism Diagnostic Observation Schedule (Lord et al., 1996).

\section{Comparison Group}

Two audiocassette archives were used to assemble a comparison set of conversational speech data from speakers with typical speech development. Inclusionary criteria for participants in the Comparison Group (CG) were (a) age within the range of the 30 individuals with HFA or AS; (b) speech status classified as Normal Speech Acquisition (NSA) on the Speech Disorders Classification System (Shriberg, Austin, Lewis, McSweeny, \& Wilson, 1997b); and (c) normal cognitive, sensory-motor, and psychosocial function, as determined by protocols used in the databases. One of the two reference databases included speech samples from typically speaking individuals who made up a control group for a study of speech disorders in adolescents (Flipsen, Shriberg, Weismer, Karlsson, \& McSweeny, 1999). The other database included speech samples from typically speaking relatives of probands assessed in a genetics study (Lewis $\&$ Shriberg, 1994). The comparison sample included conversational speech samples from 23 (43\%) typically speaking 10 - to 20 -year-old male speakers and 30 (57\%) typically speaking 20 - to 30 -year-old male speakers. The mean age of the 53 speakers was 26.4 years $(S D=12.7$ years), and their average number of words per utterance was $9.2(S D=3.1)$. Statistical tests $(t$ test $)$ of the ages and number of words processed for CG speakers compared to HFA and AS speakers were nonsignificant.

\section{Phonetic Transcription and Prosody-Voice Coding Videotaped Samples}

Pilot studies indicated that the technical quality and the linguistic content of the videotaped standardized clinical ADOS interview (Lord et al., 1996) met criteria for narrow phonetic transcription and prosody-voice coding (Shriberg, 1986). Although the duration of the interviews was comparable for speakers with HFA and AS (approximately 30 minutes), there were between-group differences in the length of the samples needed to meet criteria for processing the speech and prosody-voice analyses (see later discussion of volubility). HFA speakers required an average of 6.3 minutes $(S D=4.5)$ to produce an average of 48.9 utterances $(S D=27.3$ ) for the speech and prosody-voice analyses, whereas the AS speakers required an average of only 3.2 minutes $(S D=$ $1.8)$ to produce an average of 35.0 utterances $(S D=18.8)$. This difference between the length of the speech sample used in the speech and prosody-voice analyses was 
Table 2. Description of participants.

\begin{tabular}{|c|c|c|c|c|c|c|c|}
\hline \multirow[b]{2}{*}{ Variable } & \multicolumn{3}{|c|}{ High-Functioning Autism (HFA) } & \multicolumn{3}{|c|}{ Asperger Syndrome (AS) } & \multirow[b]{2}{*}{$p$} \\
\hline & $n$ & $M$ & $S D$ & $n$ & $M$ & $S D$ & \\
\hline Age (years) & 15 & 21.6 & 10.8 & 15 & 20.7 & 10.9 & 0.810 \\
\hline A verage W ords Per Utterance & 15 & 7.6 & 4.5 & 15 & 9.2 & 4.3 & 0.340 \\
\hline \multicolumn{8}{|l|}{ Intelligence ${ }^{a}$} \\
\hline Verbal & 15 & 96.4 & 25.8 & 15 & 106.3 & 27.7 & 0.320 \\
\hline Performance & 15 & 91.2 & 20.9 & 15 & 86.9 & 27.0 & 0.630 \\
\hline \multirow{2}{*}{\multicolumn{8}{|c|}{$\begin{array}{l}\text { Vineland A daptive Behavior } \\
\text { Scales (VABS) }\end{array}$}} \\
\hline & & & & & & & \\
\hline CommSsc & 15 & 65.7 & 19.4 & 15 & 78.1 & 24.3 & 0.140 \\
\hline DLSSS $^{d}$ & 15 & 63.1 & 24.4 & 15 & 61.8 & 22.7 & 0.880 \\
\hline SocSSe & 15 & 49.5 & 7.0 & 15 & 51.2 & 20.1 & 0.770 \\
\hline MotorSS ${ }^{f}$ & 15 & 91.1 & 21.2 & 13 & 84.1 & 25.1 & 0.430 \\
\hline CompSSg & 15 & 55.3 & 14.1 & 15 & 58.9 & 18.6 & 0.550 \\
\hline \multicolumn{8}{|l|}{$\begin{array}{l}\text { Test of Language Competence } \\
(T L C)^{h}\end{array}$} \\
\hline A mbiguous Sentences & 14 & 7.5 & 4.6 & 14 & 9.1 & 3.6 & 0.300 \\
\hline Inferences & 14 & 7.7 & 3.4 & 14 & 7.8 & 3.9 & 0.960 \\
\hline Expression & 14 & 8.2 & 4.0 & 14 & 8.3 & 4.0 & 0.960 \\
\hline Figurative Language & 13 & 7.2 & 3.8 & 14 & 8.3 & 4.0 & 0.460 \\
\hline Expressive Composite & 14 & 87.1 & 24.4 & 14 & 92.7 & 20.2 & 0.520 \\
\hline Interpretive Composite & 13 & 84.9 & 19.6 & 14 & 89.1 & 21.0 & 0.600 \\
\hline O verall Composite & 14 & 88.4 & 22.1 & 14 & 90.7 & 20.9 & 0.780 \\
\hline \multirow{2}{*}{\multicolumn{8}{|c|}{$\begin{array}{l}\text { Autism Diagnostic O bservation } \\
\text { Scalei }\end{array}$}} \\
\hline & & & & & & & \\
\hline Communication & 15 & 5.4 & 1.5 & 15 & 3.7 & 1.3 & 0.003 \\
\hline Socialization & 15 & 12.0 & 1.9 & 15 & 9.9 & 1.7 & 0.004 \\
\hline \multicolumn{8}{|c|}{ 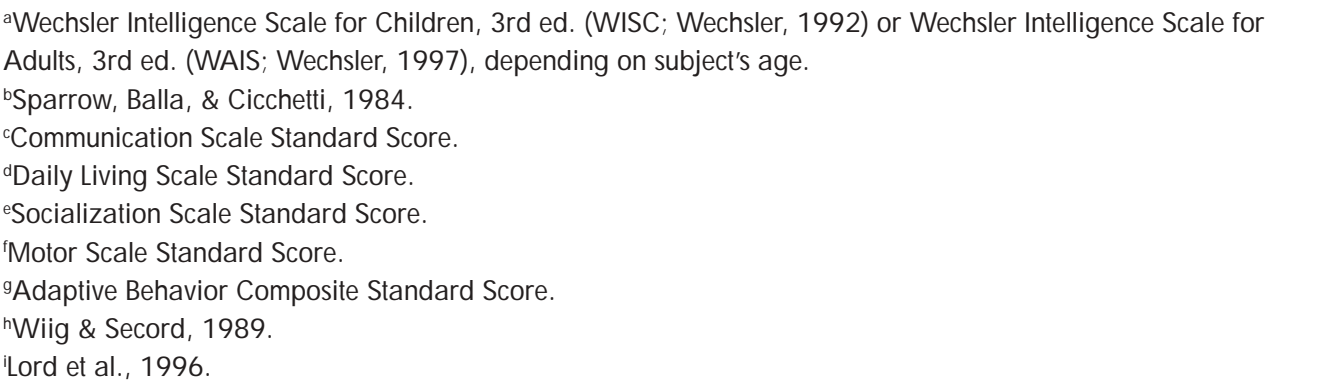 } \\
\hline
\end{tabular}

statistically significant $[t(18)=2.48, p=.023]$, but the difference in the total number of utterances used for the analyses was not $[t(24)=1.63, p<0.120]$. Phonetic transcription and prosody-voice coding of the 30 speech samples were completed by an experienced research transcriber using a Panasonic AG520B videocassette playback system and well-developed protocols referenced to adolescent and adult speakers (Shriberg, 1993; Shriberg, Austin, Lewis, McSweeny, \& Wilson, 1997a). The transcriber (third author) had participated in extensive interjudge agreement studies for both narrow phonetic transcription and prosody-voice coding (McSweeny \& Shriberg, 1995).

\section{Reliability}

To estimate the intrajudge agreement of the phonetic transcriptions and prosody-voice codes, six conversational samples (20\% of the recordings, 1,403 words) were randomly selected for retranscription and prosodyvoice coding. Ages of the 6 speakers, 4 with HFA and 2 with AS, ranged from 11 to 42 years. Intrajudge transcription reliability was calculated using software that provides point-to-point percentages of agreement for broad (i.e., disregarding diacritics used in either transcription) and narrow (i.e., including diacritics in either transcription) transcription of consonants and vowels/ diphthongs (Shriberg \& Olson, 1988). The transcriber's 
average intrajudge agreement for consonants was $98.7 \%$ for broad phonetic transcription and $94.7 \%$ for narrow phonetic transcription. For vowels, average intrajudge agreement was $93.2 \%$ for broad phonetic transcription and $89.9 \%$ for narrow phonetic transcription. Narrow transcription agreement for /s/ and /z/ distortions was $88.5 \%$ and $82.9 \%$, respectively; narrow agreement for /r/ was $100 \%$ (there were no /r/ distortions transcribed in the reliability samples).

Intrajudge agreement for prosody-voice coding was obtained using a utility program in the PEPPER software suite (Programs to Examine Phonetic and Phonological Evaluation Records; Shriberg, Allen, McSweeny, $\&$ Wilson, 2000). Agreement for the 109 utterances meeting one or more exclusion codes (to be described) was $94.5 \%$. Intrajudge agreement at the summative level of prosody-voice coding was $94.2 \%$ based on appropriate versus inappropriate prosody-voice codes for each of the six domains and $93.4 \%$ based on exact agreement for both appropriate and all inappropriate codes. Intrajudge coding agreement for the three prosody-voice domains of specific interest in this study-Phrasing, Stress, and Resonance-was as follows for four levels of agreement (from item level to summative level): Phrasing: $81.8 \%-$ 98.5\%, Stress: $46.7 \%-85.9 \%$, and Resonance: $82.6 \%-97.8 \%$.

To estimate the interjudge agreement of the phonetic transcriptions and prosody-voice codes, a second research assistant transcribed eight randomly selected conversational samples (27\% of the recordings, 1,668 words). Ages of the 8 speakers, 4 with HFA and 4 with AS, ranged from 13.7 to 37 years, with a mean age of 20.2 years. Transcription agreement was calculated using the same software as described for the intrajudge agreement estimate. The original transcriber's and second research assistant's average interjudge agreement for consonants was $98.6 \%$ for broad phonetic transcription and $92.0 \%$ for narrow phonetic transcription. For vowels, average interjudge agreement for the eight samples was $88.9 \%$ for broad phonetic transcription and $82.5 \%$ for narrow phonetic transcription. Narrow interjudge transcription agreement for /s/ and /z/ distortions was $79.8 \%$ and $77.6 \%$, respectively; narrow agreement for $/ r /$ was $97.3 \%$.

Interjudge agreement for prosody-voice coding was also obtained with the software used to estimate intrajudge agreement. Interjudge agreement for the 138 utterances meeting one or more exclusion codes (to be described) was $86.2 \%$. Interjudge agreement at the summative level of prosody-voice coding was $89.6 \%$ based on appropriate versus inappropriate prosody-voice codes for each of the six domains and $85.6 \%$ based on exact agreement for both appropriate and all inappropriate codes. Interjudge coding agreement for the three prosody-voice domains of specific interest in this study-
Phrasing, Stress, and Resonance-was as follows for the four levels of agreement (from item level to summative level): Phrasing: 73.6\%-95.8\%, Stress: $14.3 \%-86.8 \%$, and Resonance: $43.4 \%-83.3 \%$. Thus, as in other studies using this screening instrument (McSweeny \& Shriberg, 1995, in press), certain prosody-voice codes have marginal or inadequate interjudge reliability at the most detailed levels of comparison (generally involving relatively few occurrences of each code). Whereas findings at the summative level appear to have adequate reliability, individual code-level reliability findings in some domains must be interpreted with caution.

\section{Results \\ Speech Findings \\ Volubility}

Volubility for each HFA and AS speaker was computed by dividing the elapsed time of the conversational speech sample used for the present study by the number of words transcribed. Thus, examiner utterances, which were standardized by the ADOS protocol, could be included in the total sample length. Words-per-minute data could not be calculated for CG speakers because many different examiners obtained these samples, and their length of response to widely varying topics was unconstrained by a standardized protocol. Speakers with AS were significantly more voluble than HFA speakers. AS speakers averaged 96.6 words per minute $(S D=32.1)$ compared with 64.6 words per minute $(S D=37.8)$ for HFA speakers $[t(27)=2.5, p=.019]$.

\section{Severity of Involvement}

The PEPPER software suite was used to calculate and describe the frequencies and types of consonant and vowel/diphthong errors in conversational speech. The frequency (i.e., severity of involvement) comparisons between HFA and AS speakers included analyses of six summative metrics using Wilcoxon-Mann-Whitney nonparametric statistics to test for significant betweengroup differences in percentage scores. The six severityof-involvement metrics (cf. Shriberg et al., 1997a) included calculation of the following percentage data: (a) any type of consonant error (Percentage of Consonants Correct), (b) any type of vowel/diphthong error (Percentage of Vowels/Diphthongs Correct), (c) any combination of consonant and vowel/diphthong errors (Percentage of Phonemes Correct), (d) only consonant deletion and/or substitution errors (Percentage of Consonants Correct-Revised), (e) only vowel or diphthong deletion or substitution errors (Percentage of Vowels/ Diphthongs Correct-Revised), and (f) the percentage of words in the sample that were intelligible to the transcriber (Intelligibility Index). 
There were no statistically significant betweengroup differences on any of the six speech severity metrics. Percentage-correct scores on all individual and combined measures of consonant and vowel/diphthong production in conversation, as well as the percentage of intelligible words, averaged from $93 \%$ to over $99 \%$ for both the adolescent and adult speakers in the HFA and AS groups. Individual scores for speakers within each group ranged from $79.9 \%$ to $100 \%$ on the Percentage of Consonants Correct (PCC) metric (which scores clinical distortions as incorrect) and from $79.8 \%$ to $100 \%$ on the Intelligibility Index. Although not significantly lower than scores for the CG group, the range of speech competence in the HFA and AS speakers included some speakers with notably lower scores than obtained for the typical speakers in the comparison group (PCC: $M=$ 98\%, range $=88.9 \%-100 \%$; Intelligibility Index: $M=$ $99.5 \%$, range $=96.0 \%-100 \%)$.

\section{Residual Articulation Errors}

PCC scores as low as approximately $80 \%$ for both the HFA and AS speakers in the presence of markedly higher PCC-R scores (see above) indicated that some of these adolescent and adult speakers were making residual speech-sound distortion errors. Table 3 is a summary of the residual articulation error findings for the 15 speakers in each group. To be classified as having residual distortion errors on the Speech Disorders Classification System (SDCS), speakers older than 9 years (i.e., all the speakers in the present study) had to have a minimum of two of the same type of residual distortion error (e.g., dentalized sibilants, derhotacized rhotic consonants and/or vowels) on each of at least two different word types (Shriberg et al., 1997b). Because of the sampling criteria used to construct the comparison group-Normal Speech Acquisition as classified by the SDCS software-it was not appropriate for comparison purposes to estimate the percentage and types of distortion errors in the comparison speakers.

As shown in Table 3, HFA and AS speakers who met a type-token criterion of four to six distortion errors were tallied under the column titled Marginal Frequency of Residual Distortion Errors. Speakers who met a more stringent criterion of more than six sounds transcribed with the same distortion diacritic were tallied under the column titled Nonmarginal Frequency of Residual Distortion Errors. For participants who had more than one error type meeting these criteria, both distortion error types were used in the percentage calculations. Thus, the comparisons in Table 3 assess whether there were between-group differences in both the number of participants with residual distortion errors and in the types of distortions. One class of common clinical distortions (cf. Shriberg, 1993, Appendix) was dentalized or lateralized productions of one or more of the sibilant consonants $(/ \mathrm{s} /, / \mathrm{z} /, / \mathrm{J} /, / 3 /, / \mathrm{f} /, / \mathrm{d} / /)$. The other class of common clinical distortions was errors on one or more of the two liquid consonants and the rhotic vowels, including derhoticized productions of $/ \mathrm{r} /, / 3 \mathrm{l} /$, or $/ \curvearrowright /$, or labialized productions of /l/.

As shown in the left set of entries in Table 3, 33.3\% of the 30 speakers with HFA and AS met criteria for having one or more types of residual distortion errors. As adjusted for the two speakers whose distortion errors met criteria for both the sibilant and the liquid error classes, 5 of the 15 speakers (33.3\%) in each group met SDCS criteria for having residual distortion errors. Approximately half of these speakers with distortion errors met the less stringent, marginal criteria; and half met the more stringent, nonmarginal criteria for residual distortion errors.

As shown in the right set of entries in Table 3, the types of residual distortion errors made by speakers in each of the two groups were approximately equally

Table 3. Percentage of participants with residual distortion errors and summary of error types.

\begin{tabular}{|c|c|c|c|c|c|c|c|c|c|c|c|c|c|c|c|}
\hline & \multirow[b]{2}{*}{$n$} & \multicolumn{2}{|c|}{ Marginal } & \multicolumn{2}{|c|}{ Nonmarginal } & \multicolumn{2}{|c|}{ Total } & \multicolumn{4}{|c|}{ Sibilants } & \multicolumn{4}{|c|}{ Liquids } \\
\hline & & $n$ & $\%$ & $n$ & $\%$ & $n$ & $\%$ & $n$ & $\%^{\mathrm{b}}$ & $n$ & $\%^{b}$ & $n$ & $\%^{b}$ & $n$ & $\%^{b}$ \\
\hline HFA & 15 & 2 & 13.3 & 4 & 26.7 & $5^{a}$ & 33.3 & 3 & 42.9 & 1 & 14.3 & 2 & 28.6 & 1 & 14.3 \\
\hline Total & 30 & 5 & 16.7 & $6^{\mathrm{a}}$ & 20.0 & $10^{\mathrm{a}}$ & 33.3 & 5 & 41.7 & 2 & 16.7 & 3 & 25.0 & 2 & 16.7 \\
\hline
\end{tabular}


distributed across the two diagnostic groups. Dentalized sibilants were most prevalent (41.7\%), derhotacized $/ r /$, $13 \%$, and $/ 2 \%$ were second most frequent $(25.0 \%)$, and lateralized sibilants (16.7\%) and labialized /// $(16.7 \%)$ were the two remaining distortion error types meeting the criteria described above.

Additional analyses indicated that the average ages of the 10 speakers with residual distortion errors in the two groups were similar (HFA: $M=19.4$ years, $S D=$ 10.4 years, range $=11-36$ years; AS: $M=19.2$ years, $S D=5.9$ years, range $=12-36$ years). The five speakers with dentalized residual distortion errors were the youngest of the 10 speakers with distortions, ranging in age from 11 to 17 years. One of these speakers (age 11) also met criteria for derhotacized distortions. The ages of the remaining five speakers with lateralized, derhotas

\section{Prosody-Voice Findings}

Figure 1 and the Appendix provide the prosody-voice information referenced in the following discussion. Figure 1, termed a Prosody-Voice Profile, provides graphic and quantitative comparisons of the prosodyvoice findings among groups (HFA, AS, CG), including results of an omnibus nonparametric inferential statistic to test for differences among the three groups (Kruskal-Wallis nonparametric comparisons; Siegel \& Castellan, 1988). Pairwise, nonparametric group

Figure 1. Prosody-Voice Profile comparisons of speakers with High-Functioning A utism (H: circle), A sperger syndrome (A: square), and the control group of age-matched speakers (C: triangle). The averaged data for the abbreviations Q, N, and T in the two lower panels include decisions the PVSP coder considered Q uestionable, Non-Q uestionable, and the Total of both classifications. See text for descriptions of all other relevant terms and abbreviations.
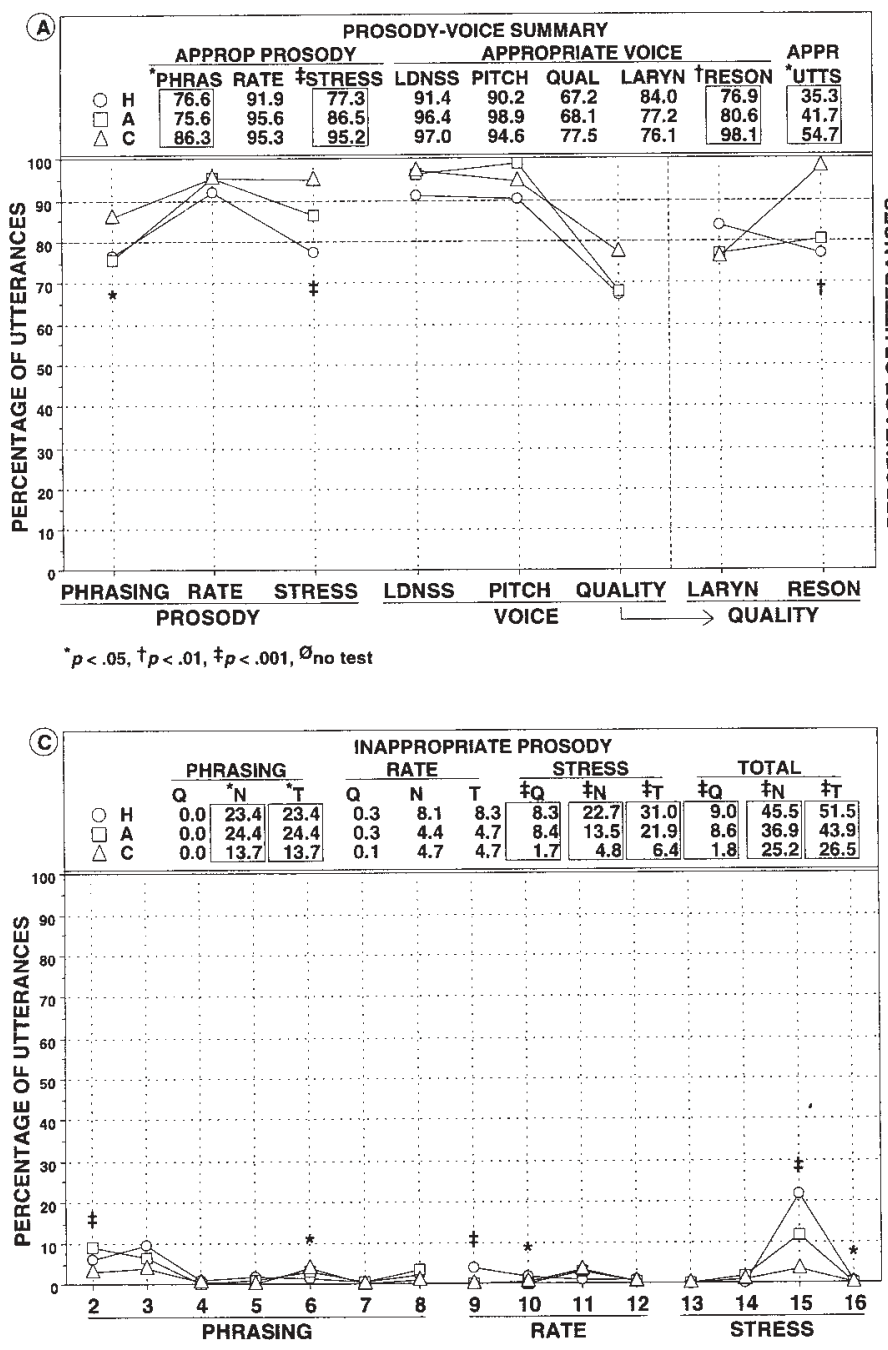

${ }^{*} p<.05, \dagger_{p<.01} \neq p<.001, \varnothing_{\text {no test }}$
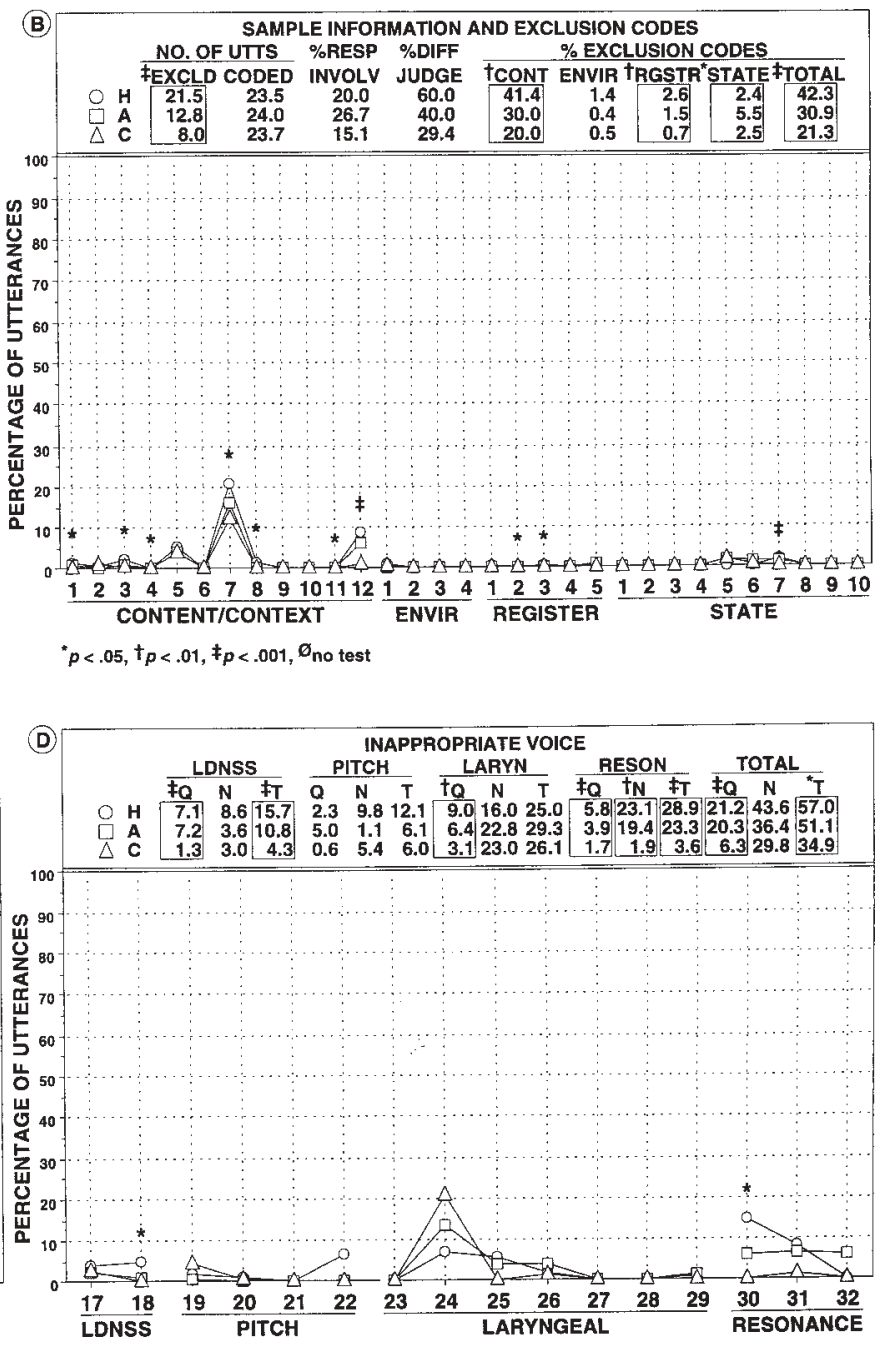

${ }^{*} p<.05, \dagger_{p}<.01, \ddagger_{p}<.001, \emptyset_{\text {no test }}$ 
comparisons (Wilcoxon-Mann-Whitney rank-order difference tests; Siegel \& Castellan, 1988) are also reported for each analysis.

\section{PVSP Exclusion Codes}

The Appendix includes the key for the Exclusion codes and Prosody-Voice codes used in the Prosody-Voice Screening Profile (PVSP; Shriberg, Kwiatkowski, \& Rasmussen, 1990). The 31 Exclusion codes are divided into four categories: Content/Context, Environment, Register, and States. These codes are used to remove an utterance from eligibility for prosody-voice coding.

Percent of excluded utterances. As indicated in Figure 1, there was a statistically significant difference among the three groups in the percentage of utterances that had to be excluded from the analyses because the utterances met criteria for one or more of the 31 exclusion codes. As shown in the upper rightmost column titled Total in Panel B, speakers with HFA averaged $42.3 \%$ excluded utterances, compared to $30.9 \%$ for speakers in the AS group and $21.3 \%$ for CG speakers. Findings for the three nonparametric pairwise tests indicated that the only statistically significant difference in the total number of excluded utterances was the comparison between HFA and CG speakers $\left(W_{x}=759.5, p=.0015\right)$.

Bases for excluded utterances. Panel B in Figure 1 indicates that most (90.3\%) of the excluded utterances from the HFA and AS speakers were due to Content/Context codes. Most frequent were C5: Interruption/Overtalk and C7: Only One Word, codes that reflect examiner and participant discourse patterns. Thus, although the HFA speakers had a large number of utterances excluded from prosody-voice coding, these exclusions were due to interactive discourse constraints, rather than reflecting inappropriate use of vegetative sounds or register variation.

\section{PVSP Prosody-Voice Codes}

Panels A, C, and D in Figure 1 provide descriptive data and the results of inferential statistical tests of prosody-voice scores for speakers in the three groups. As shown in the rightmost column in Panel A, HFA speakers averaged $35.3 \%$ utterances, or approximately one third, that were coded as having completely appropriate prosody-voice, whereas AS speakers averaged 41.7\% appropriate utterances and CG speakers 54.7\% appropriate utterances. The CG percentage is consistent with data reviewed elsewhere which indicates that typical speakers often meet PVSP criteria for inappropriate phrasing (i.e., repetitions and revisions) and/or inappropriate vocal quality (cf. McSweeny \& Shriberg, in press; Shriberg et al., 1992). Pairwise tests indicated that these summative differences in the percentages of utterances with completely appropriate prosody-voice were significant for both the HFA-CG $\left(W_{x}=355.0, p=\right.$ $.0163)$ and AS-CG $\left(W_{x}=382.0, p=.0454\right)$ comparisons.

Phrasing. The seven inappropriate Phrasing codes listed in the Appendix classify utterances that include one or more sound-, syllable-, or word-level repetitions or part-word revisions, with four of the codes indicating multiple occurrences of these behaviors within an utterance. The data in Figure 1, Panel A indicate that the three groups differed on the overall average percentage of occurrence of the seven codes. CG speakers averaged 86.3\% fluent phrasing, which is comparable to the average percentages for typically speaking children and adults reported elsewhere (cf. McSweeny \& Shriberg, in press; Shriberg et al., 1992). The HFA and AS speakers had approximately $10 \%$ lower appropriate phrasing scores, averaging $76.6 \%$ and $75.6 \%$, respectively. The average phrasing scores of speakers in the two diagnostic groups were not significantly different, but the average scores of speakers in each group were significantly different from those of the CG speakers (HFA-CG: $W_{x}=$ $379.5, p=.0395$; AS-CG: $W_{x}=345.5, p=.0105$ ). Pairwise comparisons indicated that the HFA speakers had significantly more utterances coded for PV2: Sound/ Syllable Repetition $\left(W_{x}=668.5, p=.0178\right)$, PV3: Word Repetition $\left(W_{x}=651.0, p=.0367\right)$, and PV6: One Word Revision $\left(W_{x}=362.5, p=.0146\right)$ than CG speakers. For the AS-CG comparisons, the AS speakers had significantly more utterances coded for PV2: Sound/Syllable Repetition $\left(W_{x}=737.5, p=.0006\right)$ and PV8: Repetition and Revision $\left(W_{x}=618.0, p=.0411\right)$.

Additional analyses were completed to quantify the strength of associations between Phrasing scores and the independent variables of age, average utterance length, and diagnostic group. Utterance length, measured as Average Words Per Utterance (AWU), has been shown to be negatively associated with Phrasing scores in prior work with this variable in child speech disorders; the longer the utterance the greater the opportunities for a revision or repetition on one or more words. Because AWU also had a significantly positive association with age in the present study (HFA and AS speakers: $r=.388, p=.034$; CG speakers: $r=.296, p=.031$ ), Phrasing was regressed on the two predictor variables of AWU and age. With both AWU ( $T=-3.73, p=.001)$ and age $(T=2.06, p=.049)$ statistically significant terms, the regression equation $[F(2,27)=7.18, p=.003]$ accounted for an adjusted $29.9 \%$ of the variance in Phrasing. Adding a third term for diagnostic group (HFA, AS) at any step in the equation did not increase the percentage of variance accounted for in Phrasing scores.

Rate. The four inappropriate Rate codes in the Appendix are used for utterances that include articulation rates and/or pause times that are either too slow (PV9: 
Slow Articulation / Pause Time and PV10: Slow / Pause Time) or too fast (PV11: Fast and PV12: Fast/Acceleration) relative to expected rates for persons of similar age ranges. As in prior studies, syllable rates of 4-6 per second were considered appropriate for speakers in the age range of those in this study (Odell \& Shriberg, 2001). As indicated in the numeric section of Panel A in Figure 1, over $90 \%$ of the utterances of speakers in all three groups were coded as having appropriate speech rate, although there were significant differences within this range among the three groups. The pairwise comparisons indicated that speakers with HFA had significantly more utterances coded as PV9 than the AS speakers $\left(W_{x}=\right.$ 270.0, $p=.0181)$. Similarly, they had more utterances coded as PV9 $\left(W_{x}=636.5, p=.0009\right)$ and PV10 $\left(W_{x}=\right.$ $608.0, p=.0068$ ) than the CG speakers. The magnitudes of the between-group differences in the frequencies of utterances coded for slow rate were relatively small.

Stress. The PVSP includes codes for two types of inappropriate stress as shown in the Appendix: inappropriate word or lexical stress (PV13: Multisyllabic Word Stress) and inappropriate stress at the phrase and utterance level (PV14: Reduced / Equal Stress and PV15: Excessive/Equal/Misplaced Stress). PV14 is used for stress that meets criteria for a type of monostress characterized by reduced stress on typically stressed syllables, whereas PV15 includes a form of monostress in which unstressed syllables are articulated with greater force (i.e., excessive/equal) or there is some articulatory or prosodic behavior that shifts the stress from the expected syllables/words to elsewhere in the utterance (i.e., misplaced stress).

As indicated in the numeric and graphic sections of Panel A in Figure 1, speakers in the three groups differed significantly on their average realization of linguistic stress, with CG speakers having appropriate stress on most (95.2\%) utterances, speakers with AS in the questionable range for appropriate stress (86.5\%), and speakers with HFA averaging 77.3\% utterances with appropriate stress. Results of pairwise comparisons indicated that the statistical differences obtained in the omnibus test in Figure 1 were primarily associated with PV15: Excessive/Equal/Misplaced Stress. Once again, speakers in the HFA, as compared with the AS group, did not differ on the frequency of utterances coded as inappropriate for PV15; but the average percentages for speakers in both groups $(\mathrm{HFA}=21.8 \%, \mathrm{AS}=11.8 \%$ ) were significantly different from the averaged scores (3.8\%) of the CG speakers (HFA-CG: $W_{x}=795.5, p=.0000$; AS-CG: $\left.W_{x}=745.5, p=.0004\right)$.

Additional analyses were completed for speakers in the HFA and AS groups to determine whether the inappropriate stress classified as PV15: Excessive/Equal/ Misplaced Stress was associated more with excessive/ equal stress or with misplaced stress. The PVSP coding procedure requires coders to annotate which of four subcodes for inappropriate stress met criteria for PV15. Excessive/equal stress (i.e., stress on typically unstressed syllables and forceful articulation) was one of the subcodes. The three other subcodes for PV15 classified alternative behaviors associated with misplaced stress: misplaced stress on a word, a block on a sound (as in clinical dysfluency), or a prolongation on a sound (also as in clinical dysfluency). These analyses indicated that excessive/equal stress constituted only $4 \%$ of the PV15 subcodes; the remaining $96 \%$ of subcodes indicated the occurrence of one of the three subtypes of misplaced stress. As a percentage of the total number of codes used in each group, misplaced word stress was the most frequently occurring subcode for the HFA speakers ( HFA $=39 \%, \mathrm{AS}=22 \%)$, prolongations were the most frequently occurring code for the AS speakers (HFA = $32 \%, \mathrm{AS}=54 \%$ ), and blocks were least frequent for both groups $(\mathrm{HFA}=25 \%, \mathrm{AS}=20 \%)$.

Loudness. The two PVSP codes for inappropriate Loudness, as shown in the Appendix, are PV17: Soft and PV18: Loud, which are used when at least $50 \%$ of the words in the utterance are too soft or too loud, respectively. As shown in Figure 1, over 90\% of the utterances of speakers in each of the three groups were appropriate in loudness. The pairwise comparisons indicated that significantly more of the utterances of HFA $\left(W_{x}=590.5\right.$, $p=.0086)$ and $\mathrm{AS}\left(W_{x}=590.0, p=.0090\right)$ speakers were coded PV18: Loud than were utterances of the CG group; HFA-AS comparisons on this code were nonsignificant.

Pitch. The four codes for inappropriate Pitch listed in the Appendix were used when at least $50 \%$ of the words in the utterance were too low pitched (PV19: Low Pitch/Glottal Fry, PV20: Low Pitch) or too high pitched (PV21: High Pitch / Falsetto, PV22: High Pitch) as adjusted to participants' age and sex. As shown in Figure 1, the appropriate pitch scores for all three groups averaged $90 \%$ or above. Although the Kruskal-Wallis test among the three groups indicated a significant difference for PV21 (Figure 1, graphic section of Panel D), the three pairwise Wilcoxon-Mann-Whitney tests were nonsignificant for the summative appropriate pitch comparisons and for each of the four subcode comparisons.

Quality. The summative data for Quality, as shown in Figure 1, Panel A, include weighted ratings of both Laryngeal and Resonance Quality. Although speakers in the HFA (67.2\%) and AS (68.1\%) groups averaged approximately 10 percentage points lower than the average Quality score of CG speakers (77.5\%), there were no statistically significant between-group differences.

Laryngeal quality. The seven subcodes for speakers with inappropriate laryngeal quality include a number of vocal deviations that may occur on $50 \%$ or more 
words in the utterance (PV23: Breathy, PV24: Rough, PV25: Strained) or within at least one word in the utterance (PV26: Break/Shift/Tremulous, PV27: Register Break, PV28: Diplophonia), with PV29: Multiple Laryngeal Features used for utterances meeting criteria for more than one code. Kruskal-Wallis tests of the averaged scores of speakers in all three groups indicated significant differences for PV27 and PV28, but none of the pairwise tests was significant for these inappropriate laryngeal quality codes.

Resonance quality. The data in Panels A and D of Figure 1 indicate statistically significant differences in the average resonance quality of the HFA and AS speakers compared to CG speakers. As shown in Panel A of Figure 1, CG group speakers averaged $98.1 \%$ appropriate resonance, compared to $80.6 \%$ for AS speakers and $76.9 \%$ for HFA speakers. This difference was most associated with PV30: Nasal. On this suprasegmental, compared to CG speakers (0.4\%), speakers in the HFA group had more (14.7\%) utterances in which $50 \%$ or more of words had inappropriate nasal resonance $\left(W_{x}=627.5\right.$, $p=.0059$ ).

\section{Proportion of HFA and AS Speakers With Inappropriate Prosody-Voice}

Table 4 is a summary of the proportion of speakers in each of the three groups who had more than $20 \%$ of their utterances coded as inappropriate (i.e., fail) on each of the seven summative prosody-voice variables. Twotailed tests of proportion were used to assess whether the obtained proportions of speakers with fails for a prosody-voice variable differed significantly among the three groups. As found for the previous analyses in which prosody-voice percentages were treated as continuous variables, the three groups did not differ from one another on the proportion of speakers with fails on the four prosody-voice variables of Rate, Loudness, Pitch, and Laryngeal Quality. For the remaining three variables, however, significantly more of the HFA and AS speakers had fails on Stress (HFA $=53.3 \%, \mathrm{AS}=26.7 \%$ ) than the CG speakers (5.7\%), significantly more of the HFA and AS speakers had fails on Resonance Quality ( $\mathrm{HFA}=40.0 \%, \mathrm{AS}=26.7 \%)$ than the CG speakers $(1.9 \%)$, and significantly more of the AS speakers had fails on Phrasing $(\mathrm{AS}=66.7 \%)$ than the CG speakers $(26.4 \%)$.

\section{Participant Characteristics and Speech and Prosody-Voice Findings}

An additional analysis inspected associations among participants' status on each of the cognitive, language, and adaptive functioning measures and their speech and prosody-voice scores. Preliminary analysis of the distributions for all variables indicated that most metrics did not meet the normality assumptions required for parametric correlational statistics. A number of alternatives to the Pearson correlation statistic were completed where appropriate, including analyses of Phi coefficients for dichotomized variables, point-biserial coefficients using one dichotomized and one continuous variable, and Spearman rho coefficients using rank-ordered data. For the cognitive, language, and social scales, standard scores at 1.5 standard deviations from the reference data and above were considered within the normal range, and scores below 1.5 standard deviations were considered below the normal range. For the dichotomized analyses, cutoff scores for appropriate performance on the prosodyvoice variables were set at $80 \%$ and above for appropriate performance and below $80 \%$ for inappropriate

Table 4. Percentage of speakers in each research group with more than $20 \%$ of their utterances coded as inappropriate (i.e., a "fail") on the prosody-voice screening profile.

\begin{tabular}{|c|c|c|c|c|c|c|}
\hline \multirow[b]{2}{*}{$\begin{array}{l}\text { Prosody-voice } \\
\text { variable }\end{array}$} & \multicolumn{3}{|c|}{ Group ${ }^{a}$} & \multicolumn{3}{|c|}{ Tests of proportion ${ }^{b}$} \\
\hline & $\begin{array}{c}\text { HFA } \\
(n=15)\end{array}$ & $\begin{array}{c}\text { AS } \\
(n=15)\end{array}$ & $\begin{array}{c}C G \\
(n=53)\end{array}$ & HFA vs. AS & HFA vs. CG & AS vs. CG \\
\hline \multicolumn{7}{|l|}{ Prosody } \\
\hline Phrasing & $40.0 \%$ & $66.7 \%$ & $26.4 \%$ & 0.2800 & 0.3500 & 0.0062 \\
\hline Rate & $6.7 \%$ & $0.0 \%$ & $11.3 \%$ & 1.0000 & 1.0000 & 1.0000 \\
\hline Stress & $53.3 \%$ & $26.7 \%$ & $5.7 \%$ & 0.2700 & 0.0001 & 0.0375 \\
\hline \multicolumn{7}{|l|}{ Voice } \\
\hline Loudness & $13.3 \%$ & $6.7 \%$ & $5.7 \%$ & 1.0000 & 0.3100 & 1.0000 \\
\hline Pitch & $13.3 \%$ & $0.0 \%$ & $7.6 \%$ & 0.4900 & 0.6100 & 0.5700 \\
\hline Laryngeal quality & $33.3 \%$ & $33.3 \%$ & $37.3 \%$ & 1.0000 & 1.0000 & 1.0000 \\
\hline Resonance quality & $40.0 \%$ & $26.7 \%$ & $1.9 \%$ & 0.7000 & 0.0003 & 0.0072 \\
\hline
\end{tabular}


performance. The correlation matrices for these analyses indicated only low to moderate and generally nonsignificant associations among sociodemographic, cognitive, language, and socioadaptive measures and scores on each of the six speech metrics and seven prosodyvoice variables. None of the obtained coefficients exceeded approximately $25 \%$ explained variance.

\section{$\overline{\text { Discussion }}$}

There were few significant differences in the speech and prosody-voice profiles of speakers in HFA and AS groups, and observed differences were small in absolute magnitude. Thus, although their earlier language histories may have differed, the speech and prosody characteristics of these individuals differed statistically in only a few areas at adolescence or beyond. Differences that did persist are primarily in the language domain, with the documented tendency for obsessive, repetitive topic expression by individuals with AS (Landa, 2000) reflected in the present finding of increased volubility in this sample of 15 individuals. The following discussion, therefore, focuses on comparisons of the profiles for both HFA and AS speakers with those of typically speaking individuals.

\section{Speech Findings}

An unexpected finding of this study is the high prevalence of speech-sound distortions in the HFA and AS groups. The studies summarized in the literature review indicate that articulation in these individuals is generally appropriate for their developmental levels, with most studies reporting data from younger preschool or early elementary-age speakers. The present obtained prevalence estimate of 33\% HFA and AS participants with distortion errors is high compared to typical estimates of $1 \%-2 \%$ in adult populations (Flipsen, 1999). Clinically significant speech-sound distortions (cf. Shriberg, 1993, Appendix), which involve subphonemic changes in articulatory place and manner, may reflect a speaker's failure to attend to and/or allocate resources for fine-tuning speech production to match the model of the ambient linguistic community. Klin (1992) and others have reported that children with autism failed to show the typical preference for speech-like sounds usually displayed by infants in the first months of life. A deficit in such processes could underlie, at least in part, residual articulatory errors at the allophone level that could persist for a lifetime.

\section{Prosody-Voice Findings}

Findings for the prosody-voice analyses indicated significant differences between the diagnostic and control groups in the areas of phrasing, stress, and nasal resonance.

\section{Phrasing}

Two thirds of the speakers with AS and approximately $40 \%$ of speakers with HFA were coded as having inappropriate or nonfluent phrasing on more than $20 \%$ of their utterances. The most frequent types of phrasing errors included sound/syllable/word repetitions and single-word revisions. These data suggest that many speakers with autistic syndromes produce notably disfluent speech. The disfluency appears to be unrelated to excessively fast speech because the rate differences observed between speakers in the diagnostic and CG groups were in the direction of reduced, not increased, rate.

It is interesting to speculate on the source of the obtained phrasing findings. One possibility is that the disfluency deficits may reflect perceptual and motor diatheses, similar to perspectives advanced in descriptiveexplanatory accounts of stuttering (Pore \& Reed, 1999; Wedmore, 1997). Alternatively, the observed high occurrence of repetitions and revisions may be related to formulation difficulties, such as are observed in the "mazing" behaviors of children with language-learning disabilities (Dollaghan \& Campbell, 1992). Paul (1992) has argued that, in a limited-capacity system, as is present in a child with developing language or a language disorder, a resource-demanding task can lead to disfluent production, even when disfluency is not present in low-stress situations. Paul presented data from narrative production in young children and older late talkers which suggested that narration tasks require high levels of resource allocation, producing higher-thantypical levels of disfluency in some children, as well as increased articulation errors. Thus, despite their relatively high levels of language development, as demonstrated on standardized tests (see Table 2), speakers with autistic syndromes in the present study could experience ordinary conversation as a stressful language task because of its high social knowledge and pragmatic demands. Linguistic complexity may contribute to this resource drain, as indicated by the regression findings of a significant association between utterance length and phrasing scores.

Among the three functions of prosody, these explanatory perspectives on the phrasing findings are perhaps most consistent with a deficit in the grammatical aspects of prosody. Specifically, higher levels of grammatical complexity, as indexed by greater utterance length, were associated with higher frequencies of phrasing errors. Increased resource needs from both speech motor control and social demands are relevant moderating considerations. 


\section{Stress}

Both diagnostic groups also differed significantly from typical speakers on the prosody domain of stress, keeping in mind potential reliability constraints on stress codes. Most of the inappropriate stress for HFA and AS participants involved the placement of stress cues within the utterance, rather than the grammatical use of stress or lexical stress within multisyllabic words. These stress findings indicating deficits in the domain of pragmatic or emphatic stress are consistent with those described by Baltaxe (1984) and Fine et al. (1991), who also have reported small but significant increases of misassignments of contrastive stress in HFA. Fine et al. reported normal contrastive stress use in AS, whereas the current study found small but significant contrastive stress differences for both diagnostic groups compared to typical speakers. The source of the differences in findings may be attributable to differences in statistical power for variables with relatively small effect sizes; the present report includes larger groups of both AS and typical speakers than reported in prior studies. As indicated in the per-subject data in Table 4, stress deficits were obtained for approximately one half of the individuals with HFA and one fourth of the individuals with AS.

Two explanatory views of these data concern pragmatic versus perceptual-motor sources of the stress deficits. The choice of elements to stress within a sentence is primarily a pragmatic decision. Because words containing information that is new to a listener need to be stressed (Haviland \& Clark, 1974), the speaker must keep track of what the listener is likely to consider new. Thus, difficulties with pragmatic stress assignment could reflect problems in social cognition. Alternatively, such deficits in highlighting for the listener could reflect perceptual-motor deficits in coordinating components of the speech signal. Note that such deficits would predict stress errors crossing both grammatical and pragmatic contexts, whereas the present study found errors only in the latter domain.

\section{Resonance and Other Voice Variables}

Pronovost et al. (1966) reported wide variations in pitch and loudness among speakers with autism. In the present study, individuals with HFA and AS differed from typical speakers in loudness (too loud) and pitch (too high), but the magnitudes of effects were small. For the resonance comparisons, speakers with HFA had significantly more utterances rated as nasal (20\%) than typical speakers $(2 \%)$. Moreover, the data in Table 4 indicate that more speakers with HFA (40\%) and AS (27\%) had utterances coded as too nasal than did CG speakers $(2 \%)$.

These vocal and resonance findings are especially important to listeners' perception of these speakers' affective states and hence address affective prosody. The variables of loudness, pitch, and resonance define an individual's modal register and are modulated in response to varying listener needs and speakers' emotional states. Although the obtained differences did not suggest gross involvement, even infrequent voice and resonance differences can affect listeners' perceptions of a speaker's emotional status and attractiveness. These findings are consistent with the percept of a "pedantic" style of speech often attributed to individuals with HFA and AS (Ghaziuddin \& Gerstein, 1996). Speech that is too loud and/or high pitched can create an impression of overbearing force or insistence; speech that is too slow and/or nasal may create the impression that the speaker is condescending. Such attributions may be wholly unintended on the part of the individual with autism, yet they have a powerful impact on listeners' attributions of a speaker's social-emotional state and trait. As with the relatively small difference between perceived normal disfluency rates and perceived stuttering (a rate change of 3\% to 7\%; Guitar, 1998), listeners have narrow tolerance ranges for the perception of typical or acceptable prosody-voice (cf. Shriberg \& Widder, 1990).

As suggested previously, inappropriate vocal and resonance behaviors could reflect solely social-adaptive deficits, or they could be posited to reflect deficits in sensory-motor processes. Loud, slow, high-pitched, and/ or nasal speech could be due to speech-motor control deficits, including difficulties in self-monitoring associated with poor auditory or proprioceptive feedback systems. Although formal analyses of the present data to explore these possibilities were not completed, inspection of the transcripts indicates that the vocal and resonance differences frequently occurred on short and familiar utterances, including words that were not phonetically complex. Such data would argue against the perspective of a speech-motor control deficit associated with increased cognitive-linguistic or articulatory demands. Thus, if there is a speech-motor control component in the acquisition and performance aspects of the vocal and resonance differences obtained in the present study, it would seem more likely to reflect difficulties in acquiring and self-monitoring social registers, rather than in assembling appropriate segmental and suprasegmental behaviors. This perspective would view the obtained differences in affective prosody as reflecting reduced disposition to monitor the vocal signals associated with appropriate discourse.

\section{Conclusions}

The primary goals of the present study were to profile the speech and prosody-voice characteristics of adolescents and adults with HFA or AS and to relate 
findings to the several functions of prosody. Findings generally support and extend those of the precedent literature indicating that speakers in both groups have notable deficits in prosody and that such behaviors appear to be associated more with pragmatic and affective processes than with deficits in the grammatical functions of prosody. Specifically, findings obtained for stress, loudness, pitch, and resonance were interpreted as support for this perspective, whereas the phrasing findings-which primarily reflect speech fluency-were more difficult to interpret. The increased disfluencies in speakers with autistic syndromes as compared with the typical speakers could reflect formulation constraints in making appropriate utterance choices, grammatical constraints associated with the longer utterances of some speakers, or speech-motor control constraints at the level of production or self-monitoring. On the latter explanatory possibility, the finding of a high prevalence of residual articulation errors raises interesting questions about these individuals' histories of phonological and articulatory development. Klin, Volkmar, and Sparrow (2000) report that speakers with AS have motor deficits, though in the present study there were equal proportions of HFA and AS speakers with residual articulation errors.

The research implications of the present findings clearly suggest the need for instrumental studies of the speech and prosody-voice characteristics of younger speakers with autistic syndromes. As reported, reliability estimates for the auditory-perceptual approach used in this study are generally adequate for summative levels of description, but may be inadequate in some domains for the level of precision needed in descriptiveexplanatory research. The conversational sampling approach was useful in characterizing speech and prosody-voice in discourse, but targeted analysis protocols are needed to disambiguate the several functions of prosody explored in this preliminary study. Several protocols using structured experimental tasks and acoustic methods are in development (Paul et al., 2000; Shriberg, Green, Karlsson, \& McSweeny, 2000).

Clinical implications of the present findings must be constrained to preliminary generalizations about assessment and treatment needs for adolescents and adults with autistic syndromes. The prevalence of deficits in speech and prosody-voice domains observed for the speakers in this study (see Table 4) would appear to support a recommendation for the need to at least screen speakers of this age for possible prosody-voice involvements that affect social and vocational adjustment. The speech-language pathologist needs to identify and differentiate among the types of prosody-voice involvements in an individual, remaining alert for profiles of multiple involvements. Additional analyses of the findings in Table 4 indicated that speakers had prosodyvoice involvements in as many as five of the seven domains. Once identified as problem areas, detailed review of the linguistic and social contexts under which such behaviors are most prevalent should suggest approaches to the content and form of intervention. Until additional research provides more specific guidance, traditional activities designed to increase speaker's metalinguistic knowledge of appropriate suprasegmental targets, followed by pragmatically relevant behavioral practice, would appear to be an appropriate and administratively defensible clinical objective for individuals with autistic syndromes.

\section{Acknow ledgments}

Our thanks to Chad Allen, Amy Augustyn, Madeleine Carroll, Sheryl Hall, Erica Lynne Parent, and Sara Weeks for their assistance. Preparation of this paper was supported by grants from the National Institute on Deafness and Other Communication Disorders, DC00496, and the National Institute of Child Health and Human Development, DC 03008, National Institutes of Health.

\section{References}

American Psychiatric Association. (1994). Diagnostic and statistical manual of mental disorders (4th ed.). Washington, DC: Author.

Baltaxe, C. (1981). Acoustic characteristics of prosody in autism. In P. Mittler (Ed.), Frontier of knowledge in mental retardation (pp. 223-233). Baltimore: University Park Press.

Baltaxe, C. (1984). Use of contrastive stress in normal, aphasic, and autistic children. Journal of Speech and Hearing Research, 24, 97-105.

Baltaxe, C., \& Guthrie, D. (1987). The use of primary sentence stress by normal, aphasic, and autistic children. Journal of Autism and Developmental Disorders, 17, 255-271.

Baltaxe, C., \& Simmons, J. (1985). Prosodic development in normal and autistic children. In E. Schopler \& G. Mesibov (Eds.), Communication problems in autism (pp. 95-125). New York: Plenum Press.

Baltaxe, C., \& Simmons, J. (1992). A comparison of language issues in high-functioning autism and related disorders with onset in children and adolescence. In E. Schopler \& G. Mesibov (Eds.), High-functioning individuals with autism (pp. 210-225). New York: Plenum Press.

Baltaxe, C., Simmons, J., \& Zee, E. (1984). Intonation patterns in normal, autistic and aphasic children. In A. Cohen \& M. van de Broecke (Eds.), Proceedings of the Tenth International Congress of Phonetic Sciences (pp. 713-718). Dordrecht, The Netherlands: Foris Publications.

Bartak, L., Rutter, M., \& Cox, A. (1975). A comparative study of infantile autism and specific developmental receptive language disorders: III. Journal of Autism and Childhood Schizophrenia, 6, 383-396. 
Bartolucci, G., Pierce, S., Streiner, D., \& Eppel, P. (1976). Phonological investigation of verbal autistic and mentally retarded subjects. Journal of Autism and Childhood Schizophrenia, 7, 303-316.

Bates, E., \& McWhinney, B. (1979). A functionalist approach to the acquisition of grammar. In E. Ochs \& B. Schieffelin (Eds.), Developmental pragmatics (pp. 167-211). New York: Academic Press.

Bolinger, D. (1989). Intonation and its uses: Melody in grammar and discourse. Stanford, CA: Stanford University Press.

Boucher, J., Lewis, V., \& Collis, G. (1998). Familiar face and voice matching and recognition in children with autism. Journal of Child Psychology and Psychiatry, 39, 171-182.

Crystal, D. (1986). Prosodic development. In P. Fletcher \& M. Garman (Eds.), Language acquisition (pp. 33-48). Cambridge, U.K.: Cambridge University Press.

DeMyer, M., Barton, S., DeMyer, W., Norton, J., Allen, J., \& Stelle, R. (1973). Prognosis in autism: A follow-up study. Journal of Autism and Childhood Schizophrenia, 3, 199-246.

Dollaghan, C., \& Campbell, T. (1992). A procedure for classifying disruptions in spontaneous language samples. Topics in Language Disorders, 12, 56-68.

Emmorey, K. (1987). The neurological substrates for prosodic aspects of speech. Brain and Language, 30, $305-320$.

Fay, W. (1969). On the basis of autistic echolalia. Journal of Communication Disorders, 2, 38-47.

Fay, W., \& Schuler, A. (1980). Emerging language in autistic children. Baltimore: University Park Press.

Fine, J., Bartolucci, G., Ginsberg, G., \& Szatmari, P. (1991). The use of intonation to communicate in pervasive developmental disorders. Journal of Child Psychology and Psychiatry, 32, 771-782.

Flipsen, P., Jr. (1999). Articulation rate and speech-sound normalization following speech delay. Unpublished doctoral dissertation, University of Wisconsin-Madison.

Flipsen, P., Jr., Shriberg, L. D., Weismer, G., Karlsson, H. B., \& McSweeny, J. L. (1999). Acoustic characteristics of $/ \mathrm{s} /$ in adolescents. Journal of Speech, Language, and Hearing Research, 42, 663-677.

Gerken, L. (1996). Prosody's role in language acquisition and adult parsing. Journal of Psycholinguistic Research, 25, 345-356.

Gerken, L., \& McGregor, K. (1998). An overview of prosody and its role in normal and disordered child language. American Journal of Speech-Language Pathology, 7(2), $38-48$.

Ghaziuddin, M., \& Gerstein, L. (1996). Pedantic speaking style differentiates Asperger syndrome from highfunctioning autism. Journal of Autism and Developmental Disorders, 26, 585-595.

Guitar, B. (1998). Stuttering: An integrated approach to its nature and treatment (2nd ed.). Baltimore: Williams \& Wilkins.

Hargrove, P. (1997). Prosodic aspects of language impairment in children. Topics in Language Disorders, 17(4), $76-83$.
Haviland, S., \& Clark, H. (1974). What's new: Acquiring new information as a process in comprehension. Journal of Verbal Learning and Verbal Behavior, 8, 166-169.

Heilman, K., Bowers, D., Speedie, L., \& Coslett, H. (1984). Comprehension of affective and nonaffective prosody. Neurology, 34, 917-921.

Hobson, R., Ouston, J., \& Lee, A. (1988). Emotion recognition in autism: Coordinating faces and voices. Psychological Medicine, 18, 911-923.

Hobson, R., Ouston, J., \& Lee, A. (1989). Naming emotion in faces and voices: Abilities and disabilities in autism and mental retardation. British Journal of Developmental Psychology, 7, 237-250.

Kanner, L. (1943). Autistic disturbances of affective contact. Nervous Child, 2, 217-250.

Kanner, L. (1971). Follow-up of eleven autistic children, originally reported in 1943. Journal of Autism and Childhood Schizophrenia, 2, 119-145.

Kent, R., \& Read, C. (1992). The acoustic analysis of speech. San Diego: Singular Publishing Group.

Klin, A. (1992). Listening preference in regard to speech: A possible characterization of the symptom of social withdrawal. Journal of Autism and Developmental Disorders, $21,29-42$.

Klin, A., Lang, J., Cicchetti, D. V., \& Volkmar, F. R. (2000). Interrater reliability of clinical diagnosis and DSM-IV criteria for autistic disorder: Results of the DSMIV autism field trial. Journal of Autism and Developmental Disorders, 30(2), 163-167.

Klin, A., \& Volkmar, F. (1997). Asperger syndrome. In D. Cohen \& F. Volkmar (Eds.), Handbook of autism and pervasive developmental disorders (2nd ed., pp. 94-122). New York: Wiley.

Klin, A., Volkmar, F., \& Sparrow, S. (2000). Asperger syndrome. New York: Guilford Press.

Landa, R. (2000). Social language use in Asperger syndrome and high-functioning autism. In A. Klin, F. Volkmar, \& S. Sparrow (Eds.), Asperger syndrome (pp. 125-158). New York: Guilford Press.

Lewis, B. A., \& Shriberg, L. D. (1994, November). Life span interrelationships among speech, prosody-voice, and nontraditional phonological measures. Miniseminar presented at the Annual Convention of the American Speech-Language-Hearing Association, New Orleans, LA.

Lord, C., \& Paul, R. (1997). Communication. In D. Cohen \& F. Volkmar (Eds.), Handbook of autism and pervasive developmental disorders (2nd ed., pp. 195-225). New York: Wiley.

Lord, C., Rutter, M., \& DeLavore, P. (1996). Autism diagnostic observation schedule. Unpublished manuscript, University of Chicago.

Lord, C., Rutter, M., \& LeCouteur, A. (1994). Autism Diagnostic Interview-Revised: A revised version of a diagnostic interview for caregivers of individuals with possible pervasive developmental disorders. Journal of Autism and Developmental Disorders, 24(5), 659-685.

Luks, T., Nusbaum, H., \& Levy, J. (1998). Hemispheric involvement in the perception of syntactic prosody is dependent on task demands. Brain and Language, 65, $313-332$. 
McCaleb, P., \& Prizant, B. (1985). Encoding of new versus old information by autistic children. Journal of Speech and Hearing Disorders, 50, 230-240.

McSweeny, J. L., \& Shriberg, L. D. (1995). Segmental and suprasegmental transcription reliability (Tech. Rep. No. 2). Phonology Project, Waisman Center on Mental Retardation and Human Development, University of WisconsinMadison.

McSweeny, J. L., \& Shriberg, L. D. (in press). Clinical research with the Prosody-Voice Screening Profile. Clinical Linguistics and Phonetics.

Merewether, R., \& Alpert, M. (1990). The components and neuroanatomic bases of prosody._Journal of Communication Disorders, 23, 325-336

Mesibov, G. (1992). Treatment issues with high-functioning adolescents and adults with autism. In E. Schopler \& G. Mesibov (Eds.), High-functioning individuals with autism (pp. 143-156). New York: Plenum Press.

Odell, K. H., \& Shriberg, L. D. (2001). Prosody-voice characteristics of children and adults with apraxia of speech. Clinical Linguistics and Phonetics, 15, 275-307.

Ornitz, E., \& Ritvo, E. (1976). Medical assessment. In E. Ritvo (Ed.), Autism: Diagnosis, current research, and management (pp. 7-26). New York: Spectrum Publications.

Paccia, J., \& Curcio, F. (1982). Language processing and forms of immediate echolalia in autistic children. Journal of Speech and Hearing Research, 25, 42-47.

Panagos, J., \& Prelock, P. (1997). Prosodic analysis of child speech. Topics in Language Disorders, 17(4), 1-10.

Paul, R. (1987). Communication. In D. Cohen \& A. Donnellan (Eds.), Handbook of autism and pervasive developmental disorders (pp. 61-84). New York: Wiley.

Paul, R. (1992). Speech-language interactions in the talk of young children. In R. Chapman (Ed.), Processes in language acquisition and disorders (pp. 235-254). St. Louis, MO: Mosby.

Paul, R., Augustyn, A., Chawarska, K., Klin, A., Volkmar, F., \& Cohen, D. (June, 2000). Grammatical and pragmatic prosody in high-functioning autism: A pilot study. Paper presented at the Symposium for Research in Child Language Disorders, Madison, WI.

Pierce, S., \& Bartolucci, G. (1977). A syntactic investigation of verbal autistic, mentally retarded and normal children. Journal of Autism and Childhood Schizophrenia, 7, 121-134.

Pore, S. G., \& Reed, K. L. (1999). Quick reference to speechlanguage pathology. Gaithersburg, MD: Aspen.

Pronovost, W., Wakstein, M., \& Wakstein, D. (1966). A longitudinal study of speech behavior and language comprehension in fourteen children diagnosed as atypical or autistic. Exceptional Children, 33, 19-26.

Ricks, D. (1975). Vocal communication in pre-verbal normal and autistic children. In N. O'Connor (Ed.), Language, cognitive deficits, and retardation (pp. 245-268). London: Butterworths.

Rutter, M., \& Lockyer, L. (1967). A five to fifteen year follow-up study of infantile psychosis. I: Description of sample. British Journal of Psychiatry, 113, 1169-1182.

Rutter, M., Maywood, L., \& Howlin, P. (1992). Language delay and social development. In P. Fletcher \& D. Hall
(Eds.), Specific speech and language disorders in children: Correlates, characteristics, and outcomes (pp. 63-78). London: Whurr.

Shriberg, L. D. (1986). PEPPER: Programs to examine phonetic and phonologic evaluation records. Hillsdale, NJ: Lawrence Erlbaum.

Shriberg, L. D. (1993). Four new speech and prosody-voice measures for genetics research and other studies in developmental phonological disorders. Journal of Speech and Hearing Research, 36, 105-140.

Shriberg, L. D., Allen, C. T., McSweeny, J. L., \& Wilson, D. L. (2000). PEPPER: Programs to examine phonetic and phonologic evaluation records [Computer software]. Madison, WI: Waisman Center, University of Wisconsin.

Shriberg, L. D., Aram, D. M., \& Kwiatkowski, J. (1997). Developmental apraxia of speech: III. A subtype marked by inappropriate stress. Journal of Speech, Language, and Hearing Research, 40, 313-337.

Shriberg, L. D., Austin, D., Lewis, B. A., McSweeny, J. L., \& Wilson, D. L. (1997a). The Percentage of Consonants Correct (PCC) metric: Extensions and reliability data. Journal of Speech, Language, and Hearing Research, $40,708-722$.

Shriberg, L. D., Austin, D., Lewis, B. A., McSweeny, J. L., \& Wilson, D. L. (1997b). The Speech Disorders Classification System (SDCS): Extensions and lifespan reference data. Journal of Speech, Language, and Hearing Research, 40, 723-740.

Shriberg, L. D., Green, J. R., Karlsson, H. B., \& McSweeny, J. L. (2000). Acoustics tasks to assess lexical and sentential stress. Manuscript in preparation.

Shriberg, L. D., Kwiatkowski, J., \& Rasmussen, C. (1990). The Prosody-Voice Screening Profile. Tucson, AZ: Communication Skill Builders.

Shriberg, L. D., Kwiatkowski, J., Rasmussen, C., Lof, G. L., \& Miller, J. F. (1992). The Prosody-Voice Screening Profile (PVSP): Psychometric data and reference information for children (Tech. Rep. No. 1). Phonology Project, Waisman Center on Mental Retardation and Human Development, University of Wisconsin-Madison.

Shriberg, L. D., \& Olson, D. (1988). PEPAGREE: A Program to Compute Transcription Reliability. Waisman Center Research Computing Facility, University of Wisconsin-Madison.

Shriberg, L. D., \& Widder, C. J. (1990). Speech and prosody characteristics of adults with mental retardation. Journal of Speech and Hearing Research, 33, 627-653.

Siegel, S., \& Castellan, N. J., Jr. (1988). Nonparametric statistics for the behavioral sciences (2nd ed.). New York: McGraw-Hill.

Simmons, J., \& Baltaxe, C. (1975). Language patterns in adolescent autistics. Journal of Autism and Childhood Schizophrenia, 5, 333-351.

Sparrow, S., Balla, D., \& Cicchetti, D. (1984). Vineland Adaptive Behavior Scales. Circle Pines, MN: American Guidance Service.

Tager-Flusberg, H. (1981). On the nature of linguistic functioning in early infantile autism. Journal of Autism and Developmental Disorders, 11, 45-56. 
Tager-Flusberg, H. (1995). Dissociation in form and function in the acquisition of language by autistic children. In H. Tager-Flusberg (Ed.), Constraints on language acquisition: Studies of atypical children (pp. 175-194). Hillsdale, NJ: Erlbaum.

Thurber, C., \& Tager-Flusberg, H. (1993). Pauses in the narrative produced by autistic, mentally retarded, and normal children as an index of cognitive demand. Journal of Autism and Developmental Disorders, 23, 309-322.

VanBourgondien, M., \& Woods, A. (1992). Vocational possibilities for high-functioning adults with autism. In E. Schopler \& G. Mesibov (Eds.), High-functioning individuals with autism (pp. 227-242). New York: Plenum Press.

Van Lancker, D., Canter, G., \& Terbeek, D. (1981). Disambiguation of ditropic sentences: Acoustic and phonetic cues. Journal of Speech and Hearing Research, 24, 330-335.

Van Lancker, D., Cornelius, C., \& Krieman, J. (1989). Recognition of emotional-prosodic meanings in speech by autistic, schizophrenic, and normal children. Developmental Neuropsychology, 5, 207-222.

Volkmar, F. R., Klin, A., Siegel, B., Szatmari, P., Lord, C., Campbell, M., Freeman, B. J., Cicchetti, D. V., Rutter, M., Kline, W., Buitelaar, J., Hattab, Y., Fombonne, E., Fuentes, J., Werry, J., Stone, W., Kerbeshian, J., Hoshino, Y., Bregman, J., Loveland, K., Szymanski, L., \& Towbin, K. (1994). DSM-IV Autism/Pervasive Developmental Disorder Field Trial. American Journal of Psychiatry, 151, 1361-1367.
Warren, P. (1996). Parsing and prosody: An introduction. In P. Warren (Ed.), Prosody and parsing (pp. 1-16). East Sussex, UK: Psychology Press.

Wechsler, D. (1992). Wechsler Intelligence Scale for Children (3rd ed.). San Antonio, TX: Psychological Corp.

Wechsler, D. (1997). Wechsler Adult Intelligence Scale (3rd ed.). San Antonio, TX: Psychological Corp.

Wedmore, S. (1997). Early childhood stuttering: SEA workshop participants share ideas. Advance for SpeechLanguage Pathologists and Audiologists, 7(4), 35.

Wiig, E., \& Secord, W. (1989). Test of Language Competence. San Antonio, TX: Psychological Corp.

Winner, E. (1988). The point of words: Children's understanding of metaphor and irony. Cambridge, MA: Harvard University Press.

Received December 14, 2000

Accepted April 24, 2001

DOI: $10.1044 / 1092-4388(2001 / 087)$

Contact author: Lawrence D. Shriberg, PhD, The Phonology Project, Waisman Center on Mental Retardation and Human Development, University of Wisconsin-Madison, 1500 Highland Avenue, Madison, WI 53705.

E-mail: shriberg@waisman.wisc.edu 
Appendix. Prosody-Voice Profile key for the categories and codes shown in Figure 1

\section{Exclusion Codes}

\begin{tabular}{|c|c|c|c|}
\hline Content/Context & Environment & Register & States \\
\hline $\begin{array}{l}\text { C1 Automatic Sequential } \\
\text { C2 Back Channel/Aside } \\
\text { C3 IDon't Know } \\
\text { C4 Imitation } \\
\text { C5 Internuption/ } \\
\text { Overtalk } \\
\text { C6 Not } 4(+) \text { Words } \\
\text { C7 Only One Word } \\
\text { C8 Only Person's Name } \\
\text { C9 Reading } \\
\text { C10 Singing } \\
\text { C11 Second Repetition } \\
\text { C12 Too Many } \\
\text { Unintelligibles }\end{array}$ & $\begin{array}{l}\text { E1 Intertering Noise } \\
\text { E2 Recorder Wow/ } \\
\text { Flutter } \\
\text { E3 Too Close to } \\
\text { Microphone } \\
\text { E4 Too Far from } \\
\text { Microphone }\end{array}$ & $\begin{array}{l}\text { R1 Character Register } \\
\text { R2 Narrative Register } \\
\text { R3 Negative Register } \\
\text { R4 Sound Effects } \\
\text { R5 Whisper }\end{array}$ & $\begin{array}{l}\text { S1 Belch } \\
\text { S2 Cough/Throat Clear } \\
\text { S3 Food in Mouth } \\
\text { S4 Hiccup } \\
\text { S5 Laugh } \\
\text { S6 Lip Smack } \\
\text { S7 Body Movement } \\
\text { S8 Sneeze } \\
\text { S9 Telegraphic } \\
\text { S10 Yawn }\end{array}$ \\
\hline
\end{tabular}

\section{Prosody-Voice Codes Prosody}

\begin{tabular}{|c|c|c|}
\hline Phrasing & Rate & Stress \\
\hline 1 Appropriate & \multirow{10}{*}{$\begin{array}{l}1 \text { Appropriate } \\
9 \text { Slow Articulation/Pause Time } \\
10 \text { Slow/Pause Time } \\
11 \text { Fast } \\
12 \text { Fast/Acceleration }\end{array}$} & \multirow{10}{*}{$\begin{array}{l}1 \text { Appropriate } \\
13 \text { Multisyllabic Word Stress } \\
14 \text { Reduced/Equal Stress } \\
15 \text { Excessive / Equal/ } \\
\text { Misplaced Stress } \\
16 \text { Multiple Stress Features }\end{array}$} \\
\hline 2 Sound/Syllable Repetition & & \\
\hline 3 Word Repetition & & \\
\hline 4 Sound/Syllable and & & \\
\hline Word Repetition & & \\
\hline 5 More than One Word Repetition & & \\
\hline 6 One Word Revision & & \\
\hline 7 More than One Word Revision & & \\
\hline 8 Repetition and Revision & & \\
\hline ", & & \\
\hline
\end{tabular}

Voice

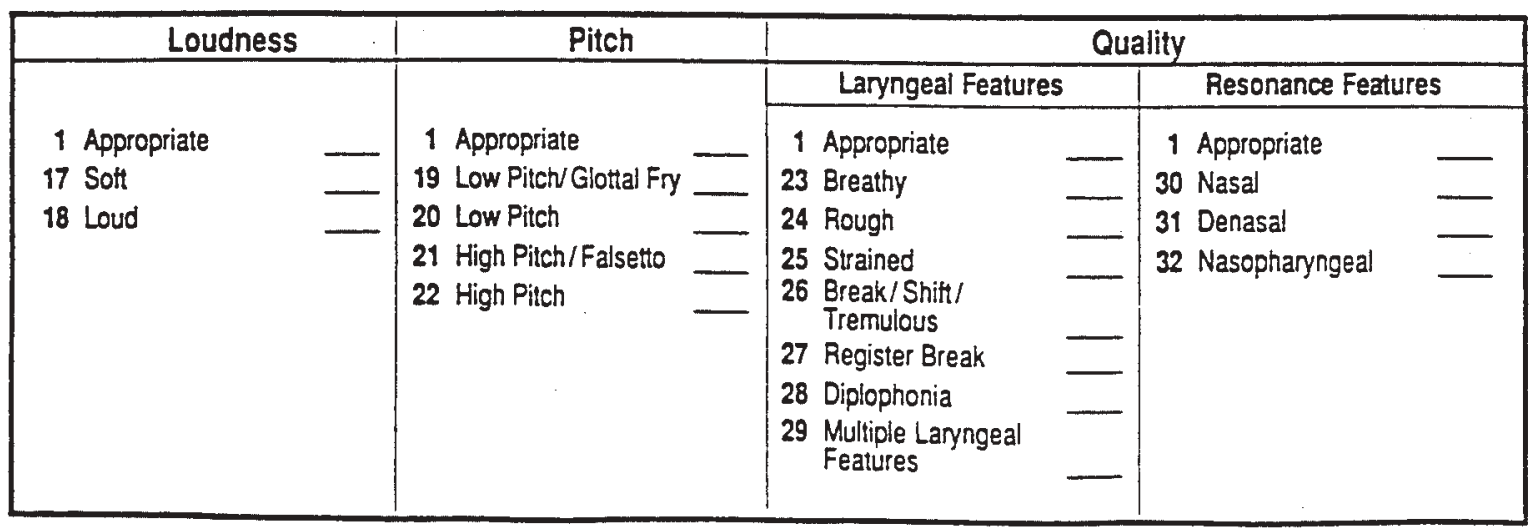

